\title{
Soft Factors and their Impact on Time to Market
}

\author{
Claes Wohlin \\ Dept. of Communication Systems \\ Lund Institute of Technology \\ Lund University \\ Box 118 \\ S-221 00 LUND \\ Sweden \\ Phone: +46-46-103329 \\ Fax: +46-46-145823 \\ E-mail: claesw@tts.Ith.se
}

\author{
Magnus Ahlgren \\ Q-Labs AB \\ IDEON Research Park \\ S-223 70 LUND \\ Sweden
}

Phone: +46-46-182987

Fax: +46-46-152880

E-mail: ma@q-labs.se

\begin{abstract}
Time to market is considered to be one of the most important quality attributes for an organization to retain its competitive edge. Soft factors are at least as important as technical issues in improving and controlling the time to market. Soft factors are used as a collective term for factors that are difficult to quantify exactly, i.e. non-technical aspects. Based on the identified importance of the soft factors, a method, incorporating the soft factors, has been developed to increase the predictability of time to market. The method consists of three main parts: model development, model usage and model maintenance. The proposed method is general, while the actual model is primarily useful for the organization for which data has been collected. The objective is twofold: first to present a general method of incorporating soft factors into the prediction of the time to market, and secondly to identify a set of critical soft factors for the organization in which data has been collected. The model is based on data collection from 12 large software projects. Time to market, effort (manhours) and a grade for 10 soft factors have been collected. The model is derived from a set of 8 projects and it is evaluated using the remaining 4 projects. The method is shown to be superior to the prediction made without taking the soft factors into account. The need to maintain the model is stressed as the model will evolve with time through new experiences gained. The proposed method can be applied in practice to help software engineers and managers to plan and control time to market and soft factors in software projects.
\end{abstract}

\section{List of keywords:}

Metrics, time to market, productivity, soft factors 


\section{Introduction}

To overcome the prevailing problems of error management, missed deadlines and overspent budgets, commercial software developers will have to embrace the concept of "measuring” projects. The latter includes all aspects of a software project, for example processes, methods, tools, organizations and also personnel resources. The area of software metrics has been studied extensively during the last decade, for example [Conte86, Fenton91]. The objective must not only be to quantify product and process quality attributes, such as reliability, productivity and time to market, but also to increase the predictability of these important attributes.

Many studies are related to tools, methods, languages etc. and their influence on, for example, fault content and code size. Some work has also been done in the area of productivity, [Boehm81, Jones86, Jones91]. Humans and other "hard to quantify aspects" are central in the development process, but these are very difficult factors to cope with. Subsequently, all of these factors are collected in the term soft factors. The term is used to describe factors that are very difficult (at least today) to measure and quantify without relying on subjective evaluation. Soft factors are studied due to the conviction, which is supported by the studies presented in [Boehm81, Boehm87], that one of the most important factors in achieving the goals of a software project is the soft factors.

The main objective of the work presented in this paper is to propose a method for predicting time to market, where the soft factors are taken into account. The objective can be subdivided into:

- Firstly, proposing a generally applicable method which can change with time as new data and experience are collected,

- Secondly, identifying which soft factors are currently being critical for the company being studied when predicting time to market.

The objective of the method is to improve the predictability of time to market as well as to provide support in the planning and controlling processes of software projects. The proposed method is based on a study of soft factors in 12 software projects. In particular, soft factors which relate to aspects that are different in different projects, although the organizations work with the same type of applications and have the same technical basis, have been examined.

The results are a refinement and further development of the method presented in [Ahlgren92] and the theoretical foundation of the method has been improved. Some weaknesses have been removed and it is believed that the method in its current form is generally applicable to software projects and organizations.

The method may be used for planning and controlling the soft factors to master time to market, instead of being surprised when the schedule can not be kept. It will be possible, depending on the requirements on time to market, to put constraints on the soft factors. To be able to fulfil the time to market requirements, managers must be able to define requirements on personnel, priority compared with other projects, the necessary requirement stability, etc. 
The method is divided into three separate parts:

1. Model development

The objective of this part is to identify a suitable model to predict and control time to market based on experience data. Model development is discussed in Section 2 This part must be performed for any organization adopting the proposed method. The derived model in itself is not general, but the way in which it is derived can be generalized.

2. Model usage

After being developed, the model may be used to predict the time to market. The use of the model is demonstrated in Section 3.

3. Model maintenance

Maintenance of the model, for example, is very important as it is expected that the model will evolve with time as new experience is gained. The model will be dynamic since the soft factors influencing time to market will probably change as new techniques are adopted. The maintenance of the model is described in Section 4.

The method is summarized in a number of steps in Section 5, and some conclusions are presented in Section 6.

\section{Model development}

\subsection{Introduction}

An investigation of the influence of the soft factors upon time to market and the interdependencies between them has been carried out for a number of large software development projects. The proposed method, and thus the model, is based on a study of 12 software projects from one company consisting of many organizations. These organizations work with the same type of application. Data were collected regarding time to market, effort and a grade of 10 soft factors which were judged as being critical in improving the predictability of time to market.

Project staffing and quality requirements on the software product are not taken into account as the data are collected from one company, and the applications being developed within the projects have similar quality requirements. The software process, which is the basis for the development, is stable. This implies that a number of important factors are stable throughout the projects being investigated and therefore it is assumed that it is reasonable to relate time to market directly to the effort expended. This assumption is the same as that made in COCOMO by Boehm, [Boehm81].

It must be noted that data collection is critical as every project only provides one data point, and hence it is not possible to wait until a statistically significant number of projects have been conducted to formulate a method, because when this happens the data from the first projects will almost certainly be obsolete. 


\subsection{Soft factors}

For the 12 projects, time to market and effort were recorded together with a grade in the range 1-5 for 10 soft factors. A grade of 5 means that the factor is judged to have been very good. An example: the hypothesis is that high requirement stability results in a fast project, which means that if it is experienced that the requirements are very stable, i.e. they do not change during the course of the project, the awarded grade will be 5. The soft factors and the definition of the grades are shown in Table I. The soft factors and grading in Table I should be regarded as an example only. When adopting a similar method to the one presented here, each organization must determine their own important soft factors and hence also the grades which are relevant to their particular application.

TABLE I. Soft factors and their grades.

\begin{tabular}{|c|c|c|c|c|c|}
\hline Soft factors & 1 & 2 & 3 & 4 & 5 \\
\hline 1. Competence & $\begin{array}{l}\text { all newly } \\
\text { employed }\end{array}$ & $\begin{array}{c}\text { many inex- } \\
\text { perienced }\end{array}$ & $\begin{array}{c}\text { normal } \\
\text { experience }\end{array}$ & $\begin{array}{l}\text { most expe- } \\
\text { rienced }\end{array}$ & $\begin{array}{l}\text { all experi- } \\
\text { enced }\end{array}$ \\
\hline 2. Product complexity ${ }^{\mathrm{a}}$ & $\begin{array}{l}\text { many very } \\
\text { difficult } \\
\text { subsystems }\end{array}$ & $\begin{array}{c}\text { many } \\
\text { difficult } \\
\text { subsystems }\end{array}$ & normal & $\begin{array}{c}\text { few } \\
\text { difficult } \\
\text { subsystems }\end{array}$ & $\begin{array}{l}\text { no difficult } \\
\text { subsystems }\end{array}$ \\
\hline 3. Requirement stability & $\begin{array}{l}\text { major and } \\
\text { many } \\
\text { changes }\end{array}$ & $\begin{array}{c}\text { changes } \\
\text { resulting in } \\
\text { major } \\
\text { problems }\end{array}$ & $\begin{array}{c}\text { changes } \\
\text { leading to } \\
\text { minor } \\
\text { problems }\end{array}$ & $\begin{array}{l}\text { minor } \\
\text { changes } \\
\text { early }\end{array}$ & no changes \\
\hline 4. Staff turnover & $\geq 10 \%$ & $6-10 \%$ & $3-5 \%$ & $1-2 \%$ & $>1 \%$ \\
\hline $\begin{array}{l}\text { 5. Geographical } \\
\text { distribution of the } \\
\text { organizations }\end{array}$ & $\begin{array}{c}>3 \text { organi- } \\
\text { zations }\end{array}$ & $\begin{array}{l}3 \text { organiza- } \\
\text { tions }\end{array}$ & $\begin{array}{c}2 \text { organiza- } \\
\text { tions }\end{array}$ & $\begin{array}{l}\text { implemen- } \\
\text { tation in } 1 \\
\text { organiza- } \\
\text { tion }\end{array}$ & $\begin{array}{l}\text { all work in } \\
1 \text { organiza- } \\
\text { tion }\end{array}$ \\
\hline 6. Methods and tools & disaster & $\begin{array}{c}\text { shortage of } \\
\text { support }\end{array}$ & $\begin{array}{l}\text { normal } \\
\text { company } \\
\text { standard }\end{array}$ & $\begin{array}{l}\text { new tech- } \\
\text { niques, no } \\
\text { problems }\end{array}$ & $\begin{array}{l}\text { advanced, } \\
\text { no } \\
\text { problems }\end{array}$ \\
\hline 7. Time pressure & very low & low & normal & high & very high \\
\hline 8. Information flow & poor & some & normal & good & very good \\
\hline 9. Priority & very low & low & normal & high & very high \\
\hline $\begin{array}{l}\text { 10. Project } \\
\text { management }\end{array}$ & $\begin{array}{l}\text { bad, no } \\
\text { control or } \\
\text { motivation }\end{array}$ & $\begin{array}{l}\text { not fully } \\
\text { controlled }\end{array}$ & normal & $\begin{array}{l}\text { good, but } \\
\text { could be } \\
\text { improved }\end{array}$ & $\begin{array}{l}\text { very good, } \\
\text { full control } \\
\text { and highly } \\
\text { motivated }\end{array}$ \\
\hline
\end{tabular}

a. Product complexity may be regarded as a non-soft factor by some persons, but we have chosen to consider it as a soft factor as long as no common agreement can be reached concerning how to measure product complexity, when taking both structural issues and problem aspects into account. 
Data from the 12 projects are presented in Table II. The ten factors are graded from 1 to 5 in the projects. Some grades could not be determined from the available information.

TABLE II. Project data for the 12 projects included in the study

\begin{tabular}{|l||c|c|c|c|c|c|c|c|c|c|c|c|}
\hline Soft factor/ Project & $\mathbf{1}$ & $\mathbf{2}$ & $\mathbf{3}$ & $\mathbf{4}$ & $\mathbf{5}$ & $\mathbf{6}$ & $\mathbf{7}$ & $\mathbf{8}$ & $\mathbf{9}$ & $\mathbf{1 0}$ & $\mathbf{1 1}$ & $\mathbf{1 2}$ \\
\hline \hline 1. Competence & 3.5 & 3 & 4 & 3 & 4 & 2 & 3 & 4 & 2 & 3 & 2.5 & 3 \\
\hline 2. Product complexity & 2 & 2 & 1 & - & - & - & 2 & 5 & 3 & 4 & 3 & 1 \\
\hline 3. Requirement stability & 3 & 4 & 2 & 3 & 2 & 4 & 4.5 & 1 & 3 & 1 & 2.5 & 2 \\
\hline 4. Staff turnover & 3 & 3 & 4 & 3 & 4 & 3 & 5 & 2 & 2 & 3 & 3 & 2 \\
\hline 5. Geographical dist. & 1 & 2 & 1 & 2 & 2 & 1 & 1.5 & 5 & 1 & 3 & 2 & 1 \\
\hline 6. Methods and tools & 2.5 & 2.5 & 2 & 3 & 3 & 3 & 2 & 2 & 2 & 3 & 3 & 3 \\
\hline 7. Time pressure & 4.5 & 5 & - & 3 & 4 & 3 & 3 & 3 & 5 & 2 & 3.5 & 3 \\
\hline 8. Information flow & 4.5 & 4 & 3 & - & - & 3 & 4 & 3 & 4 & 2 & 4.5 & 3 \\
\hline 9. Priority & 4 & 1 & 3 & 3 & 3 & 3 & 4 & 3 & 5 & 2 & 3.5 & 3 \\
\hline 10. Project managem't & 4.5 & 3 & 3 & 2 & 3 & 2 & 4 & 4 & 5 & 2 & 4 & 4 \\
\hline
\end{tabular}

The grades have been set by the same person for all projects based on information obtained from project reports, and through interviews with project leaders. This means that there may be a systematic error, but probably no random errors. The judgement should thus be fair when comparing the projects.

In the general case, it is difficult to determine the grades because different people have different expectations and hence people have different scales when describing projects. The judgement of people regarding these factors is bound to be different and it only underlines the necessity of formulating good rules for determining the grades for a specific factor.

\subsection{Correlation between soft factors}

It would be naive to believe that the soft factors affect the time to market independently. In the method proposed here, the dependence is, however, not taken into consideration, as there are probably much more critical problems associated with soft factors than their inter-dependence, for example, the difficulty of correctly grading and quantifying their influence on the time to market. The correlation between the soft factors must, however, be investigated and, in the long run, taken into account as experience grows. The correlations between the soft factors are shown in Table III.

Note that there is a danger in drawing conclusions from separate correlations, since it is a complex of correlations, for example good project management is aimed at in high-priority projects, which gives rise to a good information flow, which depends upon ... and so on. 
TABLE III. Correlation table for the soft factors

\begin{tabular}{|l||c|c|c|c|c|c|c|c|c|}
\hline Soft factor & $\mathbf{1}$ & $\mathbf{2}$ & $\mathbf{3}$ & $\mathbf{4}$ & $\mathbf{5}$ & $\mathbf{6}$ & $\mathbf{7}$ & $\mathbf{8}$ & $\mathbf{9}$ \\
\hline \hline 1. Competence & - & - & - & - & - & - & - & - & - \\
\hline 2. Product compl. & -0.01 & - & - & - & - & - & - & - & - \\
\hline 3. Req. stability & -0.50 & -0.49 & - & - & - & - & - & - & - \\
\hline 4. Staff turnover & 0.28 & -0.38 & 0.39 & - & - & - & - & - & - \\
\hline 5. Geog. dist. & 0.40 & 0.86 & -0.56 & -0.25 & - & - & - & - & - \\
\hline 6. Meth. \& tools & -0.23 & -0.04 & -0.11 & -0.13 & -0.10 & - & - & - & - \\
\hline 7. Time pressure & -0.08 & -0.33 & 0.39 & 0.12 & -0.37 & -0.36 & - & - & - \\
\hline 8. Info. flow & -0.19 & -0.25 & 0.58 & 0.14 & -0.34 & -0.22 & 0.74 & - & - \\
\hline 9. Priority & -0.24 & -0.03 & 0.14 & -0.01 & -0.33 & -0.36 & 0.19 & 0.43 & - \\
\hline 10. Project man. & -0.02 & -0.06 & 0.04 & -0.23 & -0.11 & 0.54 & 0.52 & 0.67 & 0.66 \\
\hline
\end{tabular}

The correlations between the soft factors will be used in the future as a basis for factor analysis to try to improve the results. Factor analysis is one way of trying to cope with the inter-dependencies between soft factors.

\subsection{Time to market and effort}

The 12 projects are plotted in a diagram according to their time to market and Log(effort), Figure 1. It is known, from earlier studies, that the relationship between time to market and effort is non-linear [Boehm81, Kitchenham87], thus explaining the use of $\log$ (effort). It can be seen that the data points are scattered all over the diagram, which indicates that simple relationships between effort and time to market will be insufficient to explain the relationship.

A fast project is characterized by a low value of time to market / Log(effort), i.e. time to market is normalized by manpower. This entity is denoted normalized time to market. In Figure 1 this implies that project 9 is the fastest project. This is based on the assumption that all hours put into a project are productive, and hence the ability of producing a lot of work in the shortest possible time is the basis for determining what a fast project is. 


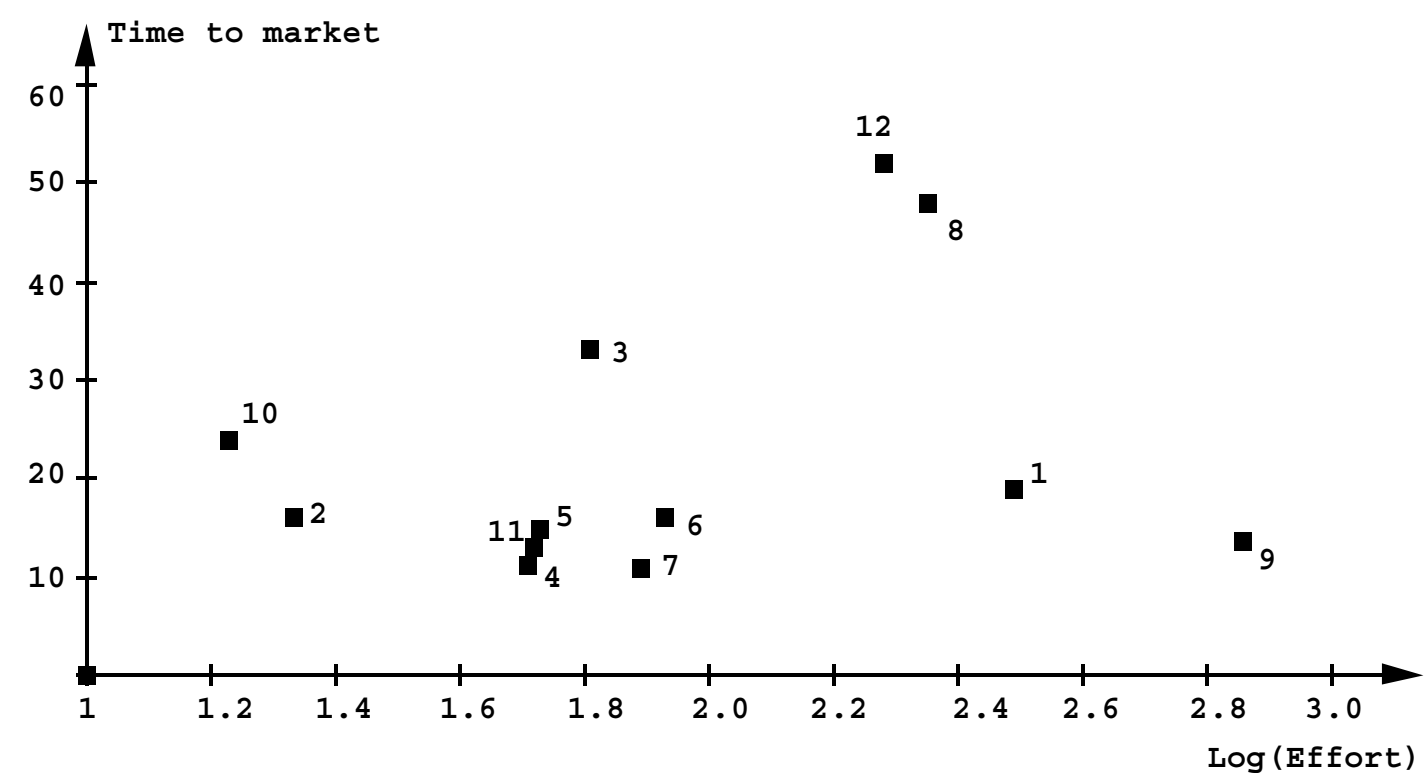

FIGURE 1. The relationship between Log(effort) and time to market

\subsection{Data analysis}

The soft factors presented in Section 2.2 are then investigated to see if they can explain the difference in normalized time to market between projects. The hypothesis is that the soft factors for a specific project may be used to make better predictions than with one single formula taking, for example, only size into account. The objective is to find a method of predicting time to market based on a known estimate of the effort or vice versa. A secondary objective is to provide a method of controlling the projects based on the knowledge of the influence of the soft factors on the normalized time to market. The latter implying that if the project must have a certain time to market, it should be possible to try to control the soft factors in such a way that the basis to obtain the required time to market is fulfilled, see also Section 3.

Eight projects were chosen randomly from the 12 projects available. The objective was to formulate the method based on these eight projects and then evaluate the method using the other four projects. The projects were numbered randomly, hence projects 1-8 were used as a basis for the method, while projects 9-12 were used for evaluation. Normally, all available data points would be used for model formulation, but since model evaluation is critical to obtain acceptance of the method this division of the projects was chosen.

Linear regression analysis and multiple linear regression analysis were applied to explain the relationship between the soft factors and the normalized time to market, but the regression techniques did not work. The application of linear regression showed that it was not possible to find one soft factor which modelled the relationship satisfactorily. Multiple linear regression improved the result, but the small number of projects made it very difficult to draw any conclusions. 
Another alternative was then tested, i.e. to correlate the soft factors one by one with the normalized time to market. Based on the correlation, the soft factors were divided into three groups, namely:

- Expected correlation: This group represents soft factors correlated to the normalized time to market in the expected direction.

- No correlation: Soft factors which are not correlated to the normalized time to market are placed in this group.

- Unexpected correlation: Some soft factors are highly correlated with the normalized time to market, but a high grade gives a slow project. This is the opposite to that which would be intuitively expected.

Correlation must be defined in this particular context. The correlation is in the interval $[-1,1]$. Based on the division into three groups, it was first decided to divide the interval into three equally sized parts. This means that a correlation of 0.34 should be considered as a correlation, but since this seems low, the boundaries were changed slightly. The correlation between soft factors and normalized time to market is denoted C. The following groups were defined:

- Expected correlation: $\mathrm{C}<-0.4$.

- No correlation: $-0.4<\mathrm{C}<0.4$

- Unexpected correlation: $C \geq 0.4$

The correlation in the "Expected correlation" group is negative due to the fact that a high grade should result in a fast project, i.e. a low value of the normalized time to market.

The correlations between the soft factors and the normalized time to market for the eight randomly chosen projects are shown in Table IV.

TABLE IV. Correlation between the different soft factors and the eight randomly chosen projects

\begin{tabular}{|l||c|c|c|c|c|c|c|c|c|c|}
\hline Factor & $\mathbf{1}$ & $\mathbf{2}$ & $\mathbf{3}$ & $\mathbf{4}$ & $\mathbf{5}$ & $\mathbf{6}$ & $\mathbf{7}$ & $\mathbf{8}$ & $\mathbf{9}$ & $\mathbf{1 0}$ \\
\hline \hline Correlation & 0.57 & 0.44 & -0.71 & -0.41 & 0.58 & -0.58 & -0.02 & -0.65 & -0.31 & 0.16 \\
\hline
\end{tabular}

According to Table IV the soft factors are grouped as follows.:

- Expected correlation:

- Requirement stability

- Staff turnover

- Methods and tools

- Information flow

- No correlation:

- Time pressure

- Priority

- Project management 


\section{- Unexpected correlation:}

- Competence

- Product complexity

- Geographical distribution of the organizations

The following three factors are found in the group "Unexpected correlation" which is a little surprising, and therefore requires comment.

- Competence: Intuitively, competence should affect time to market positively, but the figures do not support this. It would be absurd to conclude that competent personnel leads to slow projects, but it might be that competence has a higher influence upon effort than upon time to market, thus making the normalized time to market high. Another explanation is that difficult projects are staffed by highly skilled personnel, making it appear that competence does not influence time to market in the manner expected when studying the figures.

- Product complexity: This may be coupled to the problem of competence discussed above. It is likely that people with high competence are assigned to the most difficult projects.

- Geographical distribution of the organizations: Considering that the distributed units have well-specified tasks for which they are fully responsible, it is of no surprise that the impact on time to market contradicts the expectation. The projects are able to run very much in parallel.

Three factors can also be found in the group "No correlation". These factors are very difficult to explain because they are all believed to be essential in ensuring a fast project. The only sensible conclusion is that by coincidence, i.e. stochastic variations, these factors do not influence the normalized time to market. These three factors must certainly be studied further as the number of projects increases and new insight is gained. This will probably result in a change in the grouping of the soft factors, which is as expected as the model will certainly change over time.

\subsection{Project classification}

Due to the scattering of the data points, as can be seen in Figure 1, classification of the projects is needed. It is thought that there is no single relationship which explains the scattering of the data points. Therefore, the objective is to identify suitable classes and, for a particular project, place it in the correct class based on the soft factors. The number of data points is limited, hence it is not possible to divide them into a large number of classes, therefore a compromise must be accepted.

It seemed reasonable to divide the projects into three classes, a normal class, one class for projects completed faster than normal and one class for projects completed slower than normal. The classes are denoted slow, normal and fast. The eight projects were divided into classes based on an ocular inspection of Figure 1. Slow projects were: 3 and 8, normal projects: 1, 2, 5 and 6 and finally fast projects: 4 and 7 . The classes and the lines describing them are illustrated in Figure 2. The objective is to try to relate new projects to these classes thus allowing better predictions to be made than by com- 
paring with a mean value of all projects. The hypothesis is that the soft factors can be used to determine the class of the project.

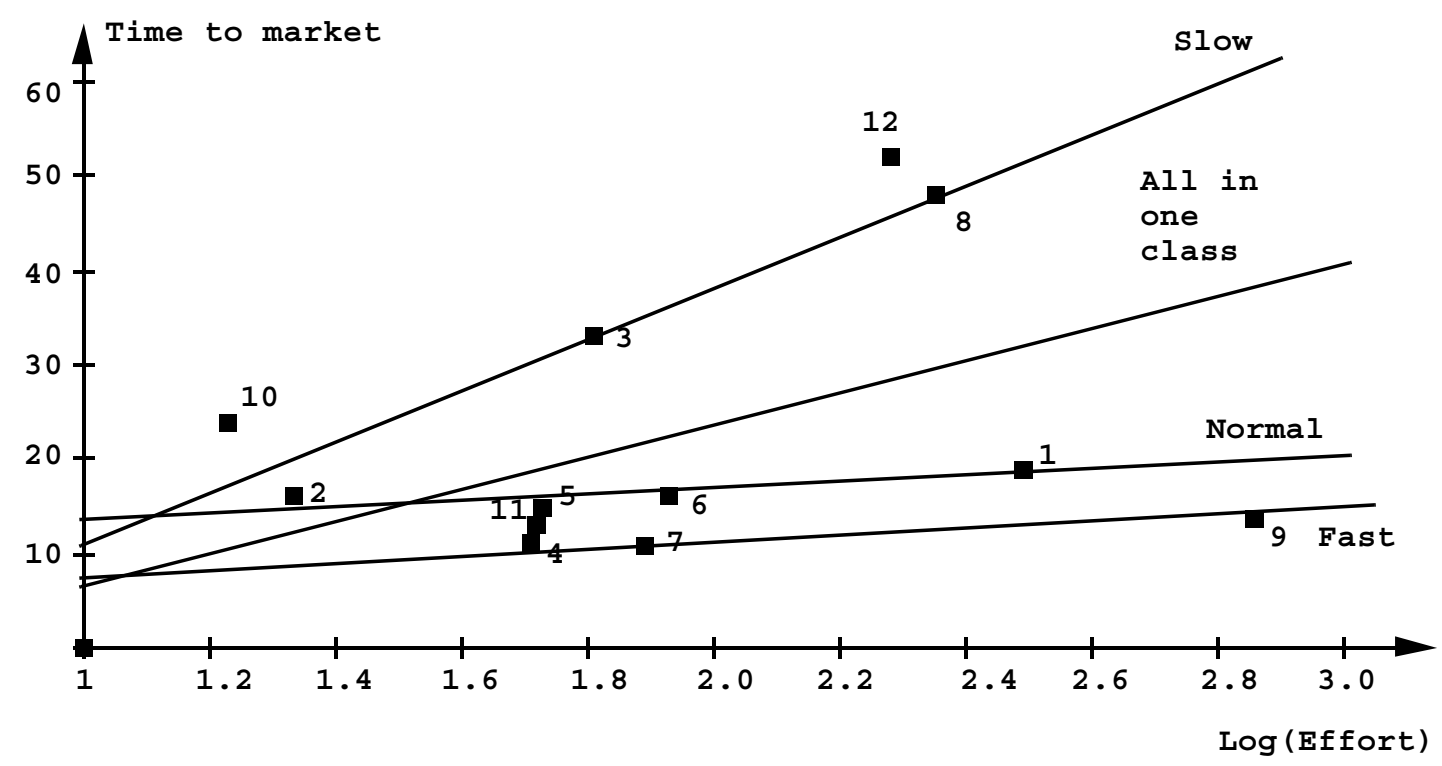

FIGURE 2. Classification of the projects into slow, normal and fast projects

The lines in Figure 2 are derived from the eight projects. The lines can be described by equations relating effort to time to market. Time to market is denoted, TTM, and effort is denoted, $\mathrm{E}$. The equations become:

Slow: $\mathrm{TTM}=-15.2+26.5 * \log (\mathrm{E})$

Normal: $\mathrm{TTM}=11.9+2.45 * \log (\mathrm{E})$

Fast: $\mathrm{TTM}=4.47+2.46 * \log (\mathrm{E})$

As a comparison, the line for all projects without classification is also shown, denoted as "All in one class" in the figure. The equation for this line is:

$\mathrm{TTM}=-11.8+17.4 * \log (\mathrm{E})$

After having presented the method to determine the class based on the soft factors for the different projects, projects 9-12 will be used for evaluation, see Section 5.2. All four equations are only valid for $\log (E) \geq 1$.

\subsection{Quantifying the soft factors}

\subsubsection{Calculation of $G$ value}

Significance values are assigned to the soft factors according to their grouping, see Section 2.5. All soft factors are given positive significance values, even if they are not correlated with the normalized time to market as expected. Intuition and belief however tell us that the significance values must be positive. 
The assignment of significance values is based on:

- Expected correlation: if intuition and the correlation correspond, then a significance value of 3 is assigned,

- No correlation: if intuition is not contradicted by the correlation, then a value of 2 is assigned,

- Unexpected correlation: if intuition is contradicted by the correlation, then a significance value of 1 is assigned.

The assignment of the significance value to the group "Unexpected correlation" may of course be debated. As stated earlier, it is believed that the soft factors have a positive influence, but the number of projects may be too small to indicate this or it may not be possible to demonstrate it due to stochastic variations, i.e. the projects studied so far happen to contradict the general behaviour. The significance values of all groups may, of course, be altered as experience of the application of this method grows.

To be able to predict time to market as well as to plan and control projects with respect to soft factors, the effect of the soft factors must be quantified. This implies that it must be possible to calculate a value which indicates the type of project to be obtained. A soft factor goodness value ( $G$ value) must be calculated. This is done in the following way.

1. The grade of the soft factor (1-5, according to the assigned numbers) is multiplied by its significance value ( 3,2 or 1 , according to the grouping of the soft factors).

2. The values from 1 above are summed for all the soft factors being graded.

3. The sum from above is divided by the number of factors being graded (in our case a maximum of 10 factors). The $G$ value is thus obtained.

The hypothesis is that the $G$ value indicates how good the soft factors are in a specific project. The following $\mathrm{G}$ values were obtained in the 12 projects:

TABLE V. G values for the projects studied.

\begin{tabular}{|l||c|c|c|c|c|c|c|c|c|c|c|c|}
\hline Factor & $\mathbf{1}$ & $\mathbf{2}$ & $\mathbf{3}$ & $\mathbf{4}$ & $\mathbf{5}$ & $\mathbf{6}$ & $\mathbf{7}$ & $\mathbf{8}$ & $\mathbf{9}$ & $\mathbf{1 0}$ & $\mathbf{1 1}$ & $\mathbf{1 2}$ \\
\hline \hline G value & 7.15 & 6.55 & 5.67 & 6.00 & 6.62 & 6.44 & 7.50 & 5.80 & 6.90 & 4.90 & 6.85 & 5.50 \\
\hline
\end{tabular}

The $G$ values presented in Table V, for projects 1-8, can be compared with the expectations based on the lines in Figure 2. This comparison shows that projects 4 and 7 were considered to be fast projects when creating the lines in Figure 2, hence these projects ought to have relatively high $G$ values. Project 7 has the highest $G$ value, which is encouraging, but project 4 is ranked only number six out of the eight projects. The two projects considered to be slow, i.e. projects 3 and 8 , have the two lowest $G$ values of the eight projects, which supports the proposed method.

The G values for projects 9-12 will be discussed in the method evaluation presented in Section 5.2. 


\subsubsection{Correlation between $G$ value and normalized time to market}

A high $G$ value should mean that the time to market is short in relation to Log(effort). Since the significance figures are based on projects 1-8, these projects can not be used to evaluate the method, but it is of course essential that there is a relatively high correlation between the $G$ value obtained and the normalized time to market.

In an attempt to correlate the $G$ value with the normalized time to market, the correlation was found to be -0.72 (or -0.67 using rank correlation). The minus sign indicates that a high $G$ value gives a low value of the normalized time to market, i.e. a fast project, which is as expected. The correlation is rather good, i.e. it is relatively close to -1.0 .

Two points must be stressed; the importance of having impartial grades, i.e. grades that make it possible to compare projects, and the importance of an enlarged study including a large number of projects.

The $G$ value approach must be evaluated through dividing the projects into slow, normal and fast projects based on the $G$ value and then seeing if the prediction of time to market (with known effort) is better based on the knowledge of the soft factors than otherwise. This evaluation is described in Section 5.2 for projects 9-12.

\subsubsection{Project classification}

The G values make it possible to group the projects into slow, normal and fast projects. Assuming that all grades are equally probable and independent, it is possible to determine the relative length between intervals for the $G$ value. This can be stated based on an analysis of the number of combinations resulting from a certain combination of grades. In the analysis, the significance values are not taken into account, instead it is assumed that they will not alter the distribution to any large extent. The number of combinations leading to a certain sum of the grades can be calculated by solving the following equation:

$$
\mathrm{x}_{1}+\mathrm{x}_{2}+\mathrm{x}_{3}+\mathrm{x}_{4}+\mathrm{x}_{5}+\mathrm{x}_{6}+\mathrm{x}_{7}+\mathrm{x}_{8}+\mathrm{x}_{9}+\mathrm{x}_{10}=\mathrm{Z}
$$

with $1<x_{i}<5$, where $x_{i}$ is equal to the grade of soft factors $i$, and $Z$ is the sum of the grades, i.e. $10<Z<50$. The equation can be solved for all $Z$ within the given interval using the principle of inclusion and exclusion. For example, for $Z=29$, if $Y_{29}$ is the number of combinations, we obtain:

$$
Y_{29}=\left(\begin{array}{c}
28 \\
19
\end{array}\right)-\left(\begin{array}{c}
10 \\
1
\end{array}\right) \times\left(\begin{array}{c}
23 \\
14
\end{array}\right)+\left(\begin{array}{c}
10 \\
2
\end{array}\right) \times\left(\begin{array}{c}
18 \\
9
\end{array}\right)-\left(\begin{array}{c}
10 \\
3
\end{array}\right) \times\left(\begin{array}{c}
13 \\
4
\end{array}\right)=837100
$$


The solution to this type of combinatorial problem may be found for example in [Grimaldi85]. The distribution using the principle of inclusion and exclusion to determine the number of combinations is shown in Figure 3.

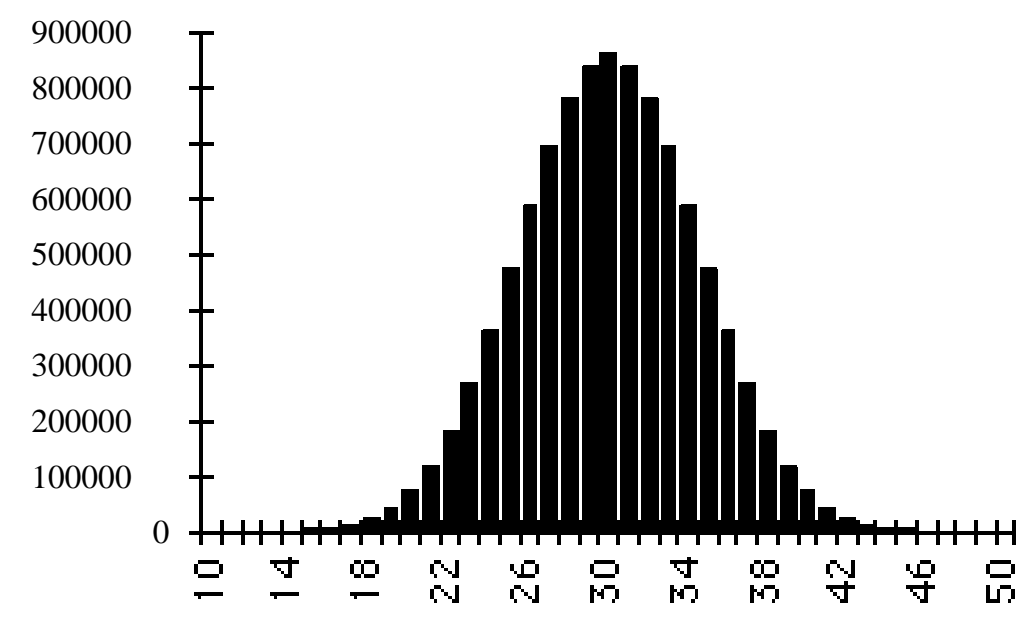

FIGURE 3. The number of combinations which give a specific sum of the grades of the $10 \mathrm{soft}$ factors, where the $x$-axis shows the sum of the grades and the y-axis shows the number of combinations.

Exactly equally probable intervals can not be obtained since it is assumed that the grades are discrete, but a good approximation is to make the end intervals five times longer than the interval for normal projects. This gives the following intervals for the $G$ value:

- $\quad$ Slow projects: $2.1<\mathrm{G}$ value $ð 5.9$

- $\quad$ Normal projects: $5.9<\mathrm{G}$ value $<6.7$

- $\quad$ Fast projects: $\quad 6.7<\mathrm{G}$ value $<10.5$

The lower limit (2.1) and the higher limit (10.5) are calculated based on the grades being 1 and 5, respectively and all 10 factors being assessed.

The definition above implies that the 8 projects will be grouped as follows:

- Slow projects: 3 and 8

- $\quad$ Normal projects: 2, 4, 5 and 6

- $\quad$ Fast projects: 1 and 7

The $\mathrm{G}$ values in Table V indicate that projects 3 and 8 are slow projects. Projects 2, 4, 5 and 6 are judged as being normal projects. Project 4 is judged to be normal, although it is a fast project according to Figure 2. The division of the projects based on the $G$ value indicates that projects 1 and 7 are fast projects. According to Figure 2, project 1 is a normal project. 


\section{Model usage}

The soft factors would be an important input to project management, especially in project planning and when predicting time to market. When the projects have been plotted in a diagram and the three lines (slow, normal and fast) drawn, as shown in Figure 2, there are two possible ways to use the diagram. These are described below together with one scenario for each.

1. Either the effort or the time to market is known (via demands or estimation):

In this case different ways of reaching the demand/estimate will be evaluated, i.e. the $G$ value can be used as a steering parameter in controlling either the effort or the time to market. An example: A project is estimated to require a certain effort. The three lines give us the possibility, depending on the requirements on time to market, to control whether the project is to be fast, normal or slow. The organization is able to manage the soft factors to obtain a $G$ value making the project fit onto the "correct" line.

\section{Scenario 1}

In this scenario, we assume that we have a demanding customer who wants the software product within 12 time units, see Figure 2, and our company wants to minimize the cost, in particular the effort spent on the development. Therefore, we must use the line for fast projects in Figure 2. To ensure that this can be achieved, we must strive to have a $G$ value which is greater or equal to 6.7 , see page 13 . This implies that we must find a combination of soft factors which leads to this particular result.

First, the grouping of the soft factors is considered, as it is more important that some factors have a high grade than others. Therefore, the focus is primarily set on the factors in the group "Expected correlation", see page 8. The requirement stability belongs to this group and hence negotiations are carried out with the customer, where it is agreed that in order to deliver within 12 time units, the customer is not allowed to change any requirement. This is clearly stated in the contract and hence the highest grade can be given to this factor, see Table VI, where the order of the soft factors in Table VI is the same as in Table I. By exploring the factors in this group further, it is obvious that it is not possible to only use people who have been at the company for a long time and who are not expected to leave, hence the staff turnover is assumed to be normal, i.e. between 3 and 5\%. The methods and tools follow the company standard. Based on this information both staff turnover as well as methods and tools can be assigned grades. Finally, the last factor in this group can be considered, i.e. information flow. The necessity for a good flow of information has been identified to achieve the goals set, hence the objective is to achieve a good flow, which leads to a high grade for information flow.

The factors belonging to the group "No correlation" are considered next. The time pressure will be high, but this particular customer does not have the highest priority from a line management perspective. Thus, the project will only have normal priority from the management. The project is, however, assigned to a project leader who has a good record, very good reputation and she is also trusted by the personnel, hence leading to a high grade. 
Finally, the factors belonging to the group "Unexpected correlation” are considered. The competence in the project group will be normal based on knowledge about the available personnel, and the complexity is also estimated to be normal compared with what the company is used to developing. The geographical distribution is unfortunately expected to be bad, i.e. the development will be spread over four organizations with sub-project leaders at each site. This renders a low grade for the geographical distribution.

TABLE VI. Soft factors and their grades for Scenario 1.

\begin{tabular}{|l||c|c|c|c|c|c|c|c|c|c|}
\hline Soft factor & $\mathbf{1}$ & $\mathbf{2}$ & $\mathbf{3}$ & $\mathbf{4}$ & $\mathbf{5}$ & $\mathbf{6}$ & $\mathbf{7}$ & $\mathbf{8}$ & $\mathbf{9}$ & $\mathbf{1 0}$ \\
\hline \hline Grade & 3 & 3 & 5 & 3 & 1 & 3 & 4 & 4 & 3 & 5 \\
\hline
\end{tabular}

This means that all 10 soft factors have been assigned grades and it is now possible to derive the $G$ value and hopefully it will be greater or equal to 6.7, otherwise it is recommendable to try to change the prerequisites of the project to increase the $G$ value and hence also the probability of project success in terms of delivery time and effort spent.

G value $=(1 * 3+1 * 3+3 * 5+3 * 3+1 * 1+3 * 3+2 * 4+3 * 4+2 * 3+2 * 5) / 10=7.6$

where the significance figures are assigned and the calculation is performed as described in Section 2.7.1. The G value is 7.6, which is clearly above the requirement of 6.7. Therefore, it is concluded that the probability of success is high and that all possible precautions have been taken to ensure control over the soft factors. The actual outcome of the factors must be monitored and the experience from the project must be included in the experience base of the company as the project is finalised.

2. The soft factors, i.e. the $\mathrm{G}$ values, are known:

The prediction line is determined from the $G$ value. By determining the time to market or the effort, the other can be obtained.

\section{Scenario 2}

This scenario is based on the four projects 9-12, which were not included in the development of the model. For the four projects, time to market can be predicted based on the fact that the soft factors and effort are known. The soft factors must be determined based on knowledge of how the project is going to be staffed, managed and so forth. It is assumed that this has been done and that the factors have been given grades according to Table II, while the resulting $G$ values are presented in Table VII. The $G$ values form the basis for identifying which of the three lines to use for the prediction of time to market. The formulas for prediction can be found on page 10. Time to market can be predicted based on knowledge of the estimated effort. The logarithm of the latter is shown in Table VII, hence we can obtain the predicted time to market. 
TABLE VII. Predictions of time to market and relative error compared with the correct time to market (Three classes).

\begin{tabular}{|l||c|c|c|c|}
\hline Factor & $\mathbf{9}$ & $\mathbf{1 0}$ & $\mathbf{1 1}$ & $\mathbf{1 2}$ \\
\hline \hline G value & 6.90 & 4.90 & 6.85 & 5.50 \\
\hline Line to use & Fast & Slow & Fast & Slow \\
\hline Log(Effort) & 2.85 & 1.22 & 1.72 & 2.26 \\
\hline Predicted time to market & 11.5 & 17.2 & 8.7 & 44.7 \\
\hline Correct time to market & 14.6 & 23.9 & 13.2 & 51.6 \\
\hline Relative error & $-21 \%$ & $-28 \%$ & $-34 \%$ & $-13 \%$ \\
\hline
\end{tabular}

The $\mathrm{G}$ value for project 11 is 6.85 , see Table VII, which means that the project is assumed to be a fast project according to the $G$ value classification. It must, however, be noted that the $G$ value is close to that for a normal project, which would have been more appropriate, as can be seen when studying Figure 2. The correct time to market is however assumed not to be known when performing the prediction, hence the fast line must be used in the evaluation. The same reasoning can be made for the other three projects, with the difference that these projects are all placed in the expected class when comparing with Figure 2.

In this particular case, the correct time to market is known, hence the relative error of the prediction method can be evaluated. The relative errors are shown in Table VII. This scenario would be one way of using the method, i.e. based on knowledge of the soft factors, the time to market or effort can be estimated. The relative error in the estimate is quite good and hence makes the method valuable. A further evaluation of the method is discussed in Section 5.2.

\section{Model maintenance}

The four evaluation projects must be incorporated into the basis for the choice of soft factors influencing the normalized time to market. The correlations between the normalized time to market and the ten soft factors for all 12 projects are shown in Table VIII (cf. Table IV).

TABLE VIII. Correlations between normalized time to market and the different soft factors based on 12 projects.

\begin{tabular}{|l||c|c|c|c|c|c|c|c|c|c|}
\hline Factor & $\mathbf{1}$ & $\mathbf{2}$ & $\mathbf{3}$ & $\mathbf{4}$ & $\mathbf{5}$ & $\mathbf{6}$ & $\mathbf{7}$ & $\mathbf{8}$ & $\mathbf{9}$ & $\mathbf{1 0}$ \\
\hline \hline Correlation & 0.44 & 0.07 & -0.70 & -0.34 & 0.40 & 0.02 & -0.48 & -0.75 & -0.46 & -0.15 \\
\hline
\end{tabular}

The correlations in the table and the limits presented in Section 2.7.3 give the following groupings after 12 projects.

- Expected correlation:

- Requirement stability

- Time pressure

- Information flow 
- Priority

- No correlation:

- Product complexity

- Staff turnover

- Methods and tools

- Project management

- Unexpected correlation:

- Competence

- Geographical distribution of the organizations

From the new groupings of the soft factors, it can be concluded that the grouping is not stable, which is what would be expected. It can be seen from the maintenance of the model that no factor has moved from "Expected correlation" to "Unexpected correlation" or vice versa. This is comforting, since this implies that the fluctuations are only minor and the model will thus change slowly over time. In particular, it must be noted that half of the soft factors remained in the same group.

New lines for slow, normal and fast projects (cf. Figure 2) and G values (cf. Table V) are calculated from this new division into correlation groups. The $G$ value including 12 projects are in the interval $[2.2,11.0]$. The interval has changed as the soft factors have moved in the grouping, see above. The grouping according to $G$ value, see Section 2.7.3, must also be updated due to the interval change of the $G$ value. The new limits indicate that the projects can be grouped as follows:

- Slow projects: 3, 4, 8, 10 and 12

- $\quad$ Normal projects: 2, 5, 6, 9 and 11

- $\quad$ Fast projects: 1 and 7

This division corresponds quite well with Figure 1 and the actual placing of the projects. Project 4 is the project placed most erroneously in comparison with Figure 1. The correlation between the $G$ value and the normalized time to market has decreased to -0.76 (or -0.72 using rank correlation), which is in the desired direction. It has hence been indicated that the method will become better and better as more experience is gained.

\section{Method summary}

\subsection{Description}

The steps we believe an organization must take to implement this procedure for managing soft factors can be divided into model development and model maintenance. 


\subsubsection{Model development}

First of all, effort must be put into creating an organization that is capable of controlling the soft factors to obtain predictable times to market in software projects, as well as being able to control which projects are going to be fast, normal or slow. By using diagrams, such as Figures 1 and 2, it is possible to build up a corporate understanding of the impact of soft factors and to create faster projects by focusing on relevant factors. It is important that each organization creates its own diagram and identifies its own relevant soft factors. The following steps should be followed:

- Identify soft factors believed to be relevant,

- Define measures according to the soft factors,

- Measure soft factors, time to market and effort,

- Plot a diagram of time to market related to Log(effort), identify fast, normal and slow projects and draw their lines,

- Identify the impact of the soft factors, group them in accordance with their influence on the projects, and assign significance figures to them,

- Calculate goodness values and identify the characteristics of each group.

These items can be compared with Section 2. The usage of the model has been illustrated in Section 3.

\subsubsection{Model maintenance}

The developed model must be maintained, since new projects may change the important soft factors in the model. The following tasks are very important in the maintenance of the model:

- Measure time to market and Log(effort) and update the diagram. It is very important to identify the evolution of the organization, i.e. after some time the time to market/Log(effort) relationship will hopefully have improved. This implies that new lines must be drawn in the diagram.

- Measure the soft factors to improve their grouping, thus improving the significance values as well as the goodness values.

- Identify new soft factors that are found to be important and old ones that no longer seem to be relevant, and update the soft factors accordingly.

These items are illustrated in Section 4.

\subsection{Evaluation}

The proposed method must be evaluated and compared with predictions made without taking the soft factors into account. It is assumed that the effort is known, which means that time to market can be predicted see also Section 3. The time to market is predicted for the four evaluation projects from the line denoted "All in one class". The soft factors are not considered in this calculation. The predicted time to market for the four 
projects is presented in Table IX. The correct time to market for the four projects is known, see Figures 1 and 2. The correct time to market for the four projects is also shown in Table IX.

TABLE IX. Predictions of time to market and relative errors compared with the correct time to market (“All in one class”).

\begin{tabular}{|l||c|c|c|c|}
\hline Factor & $\mathbf{9}$ & $\mathbf{1 0}$ & $\mathbf{1 1}$ & $\mathbf{1 2}$ \\
\hline \hline Predicted time to market & 38.1 & 9.5 & 17.9 & 27.6 \\
\hline Correct time to market & 14.6 & 23.9 & 13.2 & 51.6 \\
\hline Relative error & $+161 \%$ & $-60 \%$ & $+36 \%$ & $-47 \%$ \\
\hline
\end{tabular}

From the predicted time to market and the correct time to market, it is possible to calculate the relative error in the prediction. The relative error varies considerably and the time to market is in some cases underestimated and in others clearly overestimated. It can be concluded that it will not be possible to use this single line to predict time to market. It must also be observed that these predictions were performed when the effort was assumed to be known. The predictions will probably become even worse if the effort also has to be estimated.

These results can be compared with the results obtain when using the new method, see Section 3. It can concluded that the new method, which takes the soft factors into consideration, is superior. This is further discussed below.

The results, in general, seem promising, especially since this is the first study to be conducted. The correlation between $G$ value and normalized time to market is better than expected at this early stage of the development of a prediction method including soft factors. The relative error in the prediction is considerably improved. All four evaluation projects have lower relative errors when the soft factors are used to form a basis for choosing the line to use in predicting time to market. In particular, the relative errors for all four projects using this method are better than the lowest relative error when not taking the soft factors into consideration. This is seen by comparing the results in Table VII and Table IX.

It can be concluded that the results are very inspiring for the future. This model could provide us with an instrument to help us to use the potential in the soft factors to produce fast projects. In particular, we can control which projects will be slow and which will be fast.

\section{Conclusions}

Time to market is an important process quality attribute, and it is hence necessary to improve it as well as to improve its predictability. The method presented is based on a study of 12 software projects, where the influence of soft factors on the time to market was investigated. The proposed method is to some extent pragmatic, but it is believed that usefulness is more important than finding a more sophisticated theoretical method of treatment of the data. The latter will be further investigated, but for the time being it 
is more important to get the results into use, than to devote effort to further theoretical studies.

The method is divided into three parts: model development, model usage and model maintenance. These have been described and it has been shown that the new method is superior to predictions made without taking the soft factors into account. The model is assumed to change with time as new experience is gained, hence the model presented must not be used directly but the method steps can be used. It is not concluded that the soft factors important for our particular data are the most important for another organization, but it is proposed that other organizations can develop similar models based on their own specific data.

This investigation is the first, but nevertheless a promising attempt, to control the impact of the soft factors on software development projects. This implies that there is more important and interesting work to be done, before we can fully understand and control the total complex of soft factors. Two separate directions will be investigated; collection of practical experience and improvement of the theoretical models used in the method. Data must be collected from more projects and the method will evolve accordingly. The method as presented does not take the dependence between soft factors into consideration. Therefore, theoretical methods which do take the dependence into consideration must be studied. Some examples are factor analysis and neural networks.

Finally, it can be concluded that this area is relatively new and much still remains to be done, but the work done so far is inspiring for the future. It is believed that the method can be applied in practice to help software engineers and managers to handle time to market and soft factors.

\section{Acknowledgements}

We would like to thank the organizations and the people who provided us with the data. Many thanks to Mr Bo Lennselius, Q-Labs for valuable comments throughout this investigation and also to the anonymous reviewers who helped to improve the paper.

\section{References}

[Ahlgren92] Ahlgren, M. and Wohlin, C. (1992) Soft Factors and Lead Times. Proceedings EuroMetrics '92, 59-70.

[Boehm81] Boehm, B. (1981) Software Engineering Economics (Prentice-Hall, Englewood Cliffs, N.J., USA).

[Boehm87] Boehm, B. (1987) Improving Software Productivity. IEEE Computer, September, 43-57. 
[Conte86] Conte, S. D., Dunsmore, H. E. and Shen, V. Y. (1986) Software Engineering Metrics and Models (Benjamin/Cummings, Menlo Park, California, USA).

[Fenton91] Fenton, N. (1991) Software Metrics: A Rigorous Approach (Chapman \& Hall, London, Great Britain)1.

[Grimaldi85] Grimaldi, R. P. (1985) Discrete and Combinatorial Mathematics (Addison-Wesley, Reading, USA).

[Jones86] Jones, C. (1986) Programming Productivity (McGraw-Hill, New York, USA).

[Jones91] Jones, C. (1991) Applied Software Measurement (McGraw-Hill, New York, USA).

[Kitchenham87] Kitchenham B. (1987) Management Metrics, in Software Reliability Achievement and Assessment, Littlewood B. (ed) (Blackwell Scientific Publications). 